Título artículo / Títol article:
A Longitudinal Examination of Different Etiological Pathways to Alcohol Use and Misuse

Autores / Autors

Laura Mezquita, Manuel I. Ibáñez, Jorge Moya, Helena Villa, Generós Ortet

Revista:

Alcoholism-Clinical and experimental research, (2014), v. 38 (6)

Versión / Versió:

Cita bibliográfica / Cita bibliogràfica (ISO 690):
Postprint de l'autor

MEZQUITA, Laura; IBÁÑEZ, Manuel I.; MOYA, Jorge; VILLA, Helena; ORTET, Generós. A Longitudinal Examination of Different Etiological Pathways to Alcohol Use and Misuse. AlcoholismClinical and experimental research, (2014), 6 (38), p. 1770-1779

url Repositori UJI: 


\title{
A Longitudinal Examination of Different Etiological Pathways to Alcohol Use and Misuse
}

\author{
Laura Mezquita, Manuel I. Ibáñez, Jorge Moya, Helena Villa, and Generós Ortet
}

\begin{abstract}
Background: Sher, Grekin, and Williams (2005) pointed out the existence of 4 main etiological, but not mutually exclusive, models that might explain the development of alcohol use and misuse. The aim of the present study was to explore 3 of these 4 pathways in which psychological (personality and drinking motives) and environmental (child maltreatment) variables may play a relevant role: positive affect regulation, negative affect regulation, and deviance proneness.

Methods: Three hundred and fourteen young adults in the 18 to 29 year age range completed different personality, alcohol use, and child maltreatment questionnaires at Time 1. Five years later, they responded to drinking motives, antisocial behavior, alcohol use, and alcohol-related problems questionnaires.

Results: The path analyses showed that emotional abuse predicted negative emotionality, which, in turn, prospectively predicted alcohol-related problems through coping-with-depression drinking motives (negative affect regulation). Emotional neglect predicted lesser positive emotionality, and physical abuse predicted unconscientious disinhibition personality characteristics. In turn, these 2 broad personality domains predicted drinking at weekends at Time 2 through enhancement drinking motives (positive affect regulation). Finally, physical neglect predicted disagreeable disinhibition, and both disinhibition domains directly predicted antisocial behavior 5 years later which, in turn, predicted drinking at weekends, drinking on weekdays, and alcohol-related problems (deviance proneness).

Conclusions: The findings describe the specific role of distal (maltreatment and personality) and more proximal (antisocial behavior and drinking motives) variables in the different pathways involved in the development of alcohol use and misuse.
\end{abstract}

Key Words: Child Maltreatment, Personality, Drinking Motives, Alcohol, Etiological Pathways.

A LCOHOL CONSUMPTION IS causally related to more than 60 different medical conditions, and is estimated to be the world's third largest risk factor for disease and disability (World Health Organization, 2011). A better understanding of the etiological pathways involved in different alcohol consumption patterns and alcohol misuse could help to develop more reliable and efficient prevention and treatment programs (Conrod et al., 2011). Sher and colleagues (2005) proposed the existence of 4 etiological, but not mutually exclusive, models that can explain the development of alcohol use disorders. These are (i) positive affect regulation; (ii) negative affect regulation; (iii) deviance proneness; and (iv) pharmacological vulnerability. The present study focuses on the first 3 pathways in which personality and psychosocial variables play a more relevant role (Ibáñez et al., 2008).

From the Department of Basic and Clinical Psychology and Psychobiology (LM, MII, HV, GO), Universitat Jaume I, Castelló, Spain; and Department of Pedagogy and Psychology (JM), Universitat de Lleida, Spain.

Received for publication July 30, 2013; accepted March 5, 2014.

Reprint requests: Laura Mezquita, PhD, Department of Basic and Clinical Psychology and Psychobiology, Universitat Jaume I, Av. de Vicent Sos Baynat, s/n, 12071 Castelló, Spain; Tel.: + 34964729706; Fax: + 34964729267; E-mail:Imezquit@uji.es

Copyright $(2014$ by the Research Society on Alcoholism.

DOI: 10.1111/acer.12419

\section{Positive Affect Regulation}

The positive affect regulation pathway refers to people who drink alcohol "to get high" or "because it makes me feel good"; that is, people who drink to experience positive alcohol reinforcement effects. These enhancement drinking motives are associated with drinking in different contexts; for instance, where heavy drinking is condoned (e.g., with samesex friends, in bars; Cooper, 1994) and drinking at weekends (Mezquita et al., 2011). Although enhancement motives are also associated with alcohol-related problems, when heavy drinking is controlled, they do not predict alcohol-related problems, which suggests that enhancement motives are indirectly related to alcohol problems through heavy drinking (Cooper, 1994; Mezquita et al., 2010).

Moreover, internal drinking motives (enhancement and coping) have been closely related to other distal variables, mainly personality. Specifically, drinking to enhance has been associated with personality traits of sensitivity to reward, low inhibitory control, sensation seeking, intensity seeking, impulsivity, low suppression of aggression, low conscientiousness, and extraversion (Cooper et al., 2000; Kuntsche et al., 2006, 2008; Mezquita et al., 2010). Consequently, impulsivity/disinhibition and positive emotionality characteristics, which have been related to alcohol use and abuse in previous studies and meta-analyses (Cooper et al., 2000; Kotov et al., 2010; Ruiz et al., 2003), may play a relevant role in the positive affect regulation pathway through enhancement drinking motives. 


\section{Negative Affect Regulation}

The second etiological pathway refers to people who drink alcohol for the purpose of diminishing negative affect states, like anxiety and depression (e.g., "to relax" or "because it helps me when I am feeling depressed"). This pathway corresponds to the "self-medication" or the tension-reduction hypothesis (Sher et al., 2005). In this case, one of the most proximal variables to problematic alcohol consumption would be coping drinking motives. Coping motives have been related to drinking alone, drinking at home, more serious alcohol consumption, and mainly with more severe alcohol-related problems (Cooper, 1994; Kuntsche et al., 2005).

Furthermore, coping motives also appear to mediate the association of personality with alcohol outcomes. Accordingly, negative emotionality characteristics have been strongly associated with coping motives (Cooper et al., 2000; Kuntsche et al., 2006; Mezquita et al., 2010), although low conscientiousness has also been related to a lesser extent to drink to cope (Kuntsche et al., 2008; Mezquita et al., 2010). These results suggest a major influence of negative emotionality, and also a less marked influence of disinhibition characteristics, in the negative affect regulation pathway.

\section{Deviance Proneness}

In the deviance proneness etiological pathway, alcohol use is considered a part of a more general, deviant pattern whose roots lie in childhood (Sher et al., 2005). Accordingly, quantitative genetic studies have shown that antisocial behavior and antisocial personality disorder share genetic factors with (i) drug use disorders, including alcohol use problems (Kendler et al., 2003), and (ii) personality characteristics of disinhibition (Krueger et al., 2002). These data indicate that disinhibitory personality and a deviant pattern of behavior can be understood to form part of vulnerability to the externalizing spectrum, which includes alcohol misuse.

In addition, the problem behavior theory posits that different environmental variables causally relate to involvement in a range of deviant behaviors (see Sher et al., 2005). Thus, it is well-established that inadequate parenting and child maltreatment have long-lasting and pervasive effects on mental health, antisocial behavior, or drug and alcohol misuse (Enoch, 2011; Norman et al., 2012). However, the potential mediators of an association between maltreatment and alcohol use and abuse have received little attention. A pervasive, long-lasting psychological characteristic, such as personality, may constitute a plausible candidate. Accordingly, it has been found that child maltreatment is associated with disinhibition and impulsivity that, in turn, predict alcoholrelated behaviors (Bailey and McCloskey, 2005; Lukasiewicz et al., 2008; Oshri et al., 2013; Shin et al., 2012), thus supporting the importance of maltreatment and impulsive personality in the deviance proneness pathway.

Moreover, maltreatment has been associated with emotional instability and neuroticism (Moran et al., 2010;
Nederlof et al., 2010; Rogosch and Cicchetti, 2004), and also with enhancement and coping motives (Goldstein et al., 2010). These data suggest that maltreatment might be involved in several pathways to alcohol use, and not only deviance proneness. Yet as far as we know, no previous studies have explored the psychological variables (e.g., personality characteristics) through which child maltreatment influences drinking motives and alcohol outcomes.

\section{The Current Study}

The current research work aimed to describe different etiological pathways to alcohol use by means of a prospective study, and to explore the importance and specific role of personality, motivation, and child maltreatment in each etiological pathway. Based on Sher and colleagues' (2005) proposal and previous research studies, we hypothesized the following prospective associations: (i) negative emotionality and, to a lesser extent, unconscientious disinhibition, will be related to alcohol-related problems through coping motives (negative affect regulation); (ii) unconscientious disinhibition and positive emotionality will be related to alcohol use through enhancement motives (positive affect regulation); (iii) disinhibition will be related to alcohol use outcomes through antisocial behavior (deviance proneness); and (iv) more distal variables, such as child maltreatment, will be related to alcohol outcomes through more proximal variables, such as personality which, in turn, will influence drinking motives and antisocial behavior.

\section{MATERIALS AND METHODS}

\section{Sample and Procedure}

At Time 1 (T1), 476 participants were contacted by advertisements posted around the university. They completed the child maltreatment, alcohol consumption, and personality measures. They received $20 €$ for their participation and 5 extra euros per each new participant who got in touch with the interviewers.

Five years later (Time 2 [T2]), 330 participants were contacted by phone. Those living in Castelló (east Spain) completed the assessment at the university, while those living in other cities received questionnaires by post. They answered the alcohol use scales again, together with the drinking motives, antisocial behavior, and alcohol-related problems questionnaires, and received $40 €$ for their participation.

When the mean scores of the assessed variables at T1 were compared among the participants who completed the assessment at T2 $(n=330)$ and those who did not $(n=146)$, we found that the participants who dropped the study obtained a significantly lower score on the SR scale $(t=2.07, p<0.05)$, and a higher one for alcohol consumption (weekdays: $t=4.01, p<0.001$; weekends: $t=3.23$, $p<0.01)$ and emotional neglect $(t=2.38, p<0.05)$.

We excluded those participants who indicated that they had not drunk alcohol in their whole lifetime at T2 $(n=6)$, and also those who did not answer the Modified Drinking Motives Questionnaire (M DMQ-R) questionnaire $(n=2$, see details below). Of the remaining 322 participants, those whose age was $2 \mathrm{SD}$ above the mean were excluded from the analyses in order to select an agehomogeneous sample. Thus, we carried out the analyses with 314 respondents $\left(61.5 \%\right.$ female, $M_{\text {age }}=21.2(\mathrm{SD}=2.2)$, age range $=18$ 
to 29 years at T1). According to the socio demographic characteristics, $92.0 \%$ were students, while only $8.0 \%$ reported other occupations. Five years later, $47.6 \%$ were students, $20.6 \%$ were employees, $10.9 \%$ were unemployed, and the remaining $20.9 \%$ were distributed into high entrepreneurs/senior executives $(0.3 \%)$, self-employed $(3.5 \%)$, government employees/armed forces $(7.7 \%)$, qualified employees in the industry/construction sector $(3.2 \%)$, or others $(6.2 \%)$. All the participants provided informed consent to participate in the study.

\section{Measures}

The Spanish version of the Childhood Trauma QuestionnaireShort Form (CTQ-SF; Hernández et al., 2013) assesses 5 child maltreatment types: physical, sexual and emotional abuse, and physical and emotional neglect. Each domain is measured with 5 items; response options range from $1=$ never true to $5=$ very often true.

The Spanish NEO-Five-Factor Inventory (NEO-FFI; Costa and McCrae, 1999) includes 60 items that measure the 5 domains of the Five-Factor Model (FFM) of personality (Neuroticism, Extraversion, Openness to Experience, Agreeableness, and Conscientiousness). Items are responded to on 5-point Likert scales ranging from 0 (strongly disagree) to 4 (strongly agree).

The SPSRQ-SF is the short form of the Sensitivity to Punishment (SP) and Sensitivity to Reward (SR) Questionnaire developed by Torrubia and colleagues (2001), which assesses individual differences in Gray's Behavioral Inhibition System and the Behavioral Activation System. The questionnaire is composed of 31 items and takes a dichotomous response format (yes/no) which is grouped into 2 scales: SP and SR.

The Spanish Short version of the Eysenck Personality Questionnaire-Revised (EPQ-RS; Ortet et al., 2001) assesses Eysenck's broad dimensions of psychoticism, extraversion, and neuroticism. Each scale consists of 12 items, and the response alternatives are yes/no.

The Spanish version of the Temperament and Character Inventory-Revised, the TCI-R (Gutiérrez-Zotes et al., 2004) measures Cloninger's 4 dimensions of temperament and 3 dimensions of character. In the present study, we used the scales of temperament: novelty seeking, harm avoidance, reward dependence, and persistence. Participants answered 107 items with a dichotomous response format (true/false).

The Spanish version of the M DMQ-R (Mezquita et al., 2011) consists of 28 items that assess social, coping-with-anxiety, copingwith-depression, enhancement, and conformity motives. Participants indicate how often they drink for the reason specified in each item on a 5-point Likert scale ranging from 1 (almost never/never) to 5 (almost always/always). In the present research, we used the internal drinking motives scales (coping-with-anxiety, coping-withdepression, and enhancement), which have been seen to play a relevant role in the pathways to alcohol use in previous studies.

The Antisocial Behavior Scale (ABS; Silva et al., 1996) includes 35 items describing different antisocial behaviors on a 4-point Likert scale (from 1 "never/almost never" to 4 "very often"). Item examples are "I have used knives or sticks in fights," "I have broken, ripped, or damaged public properties." or "I have stolen things from cars."

The Alcohol Intake Scale (AIS; Grau and Ortet, 1999) was used to assess drinking quantity. Participants responded with open-ended questions: how many drinks (beers, glasses of wine, liquors, and spirits) did they consume on weekdays (Monday to Thursday) and at weekends (Friday to Sunday). Then the number of Standard Drink Units (SDU) drunk were calculated after taking into account that beers and glasses of wine are the equivalent to $1 \mathrm{SDU}$, while liquors and spirits are the equivalent to 2 SDU. In Spain, an SDU is the equivalent to $10 \mathrm{~g}$ of alcohol (Rodríguez-Martos et al., 1999).
The Spanish version of the Rutgers Alcohol Problem Index (RAPI; López-Núñez et al., 2012) is a 23-item measure designed to assess alcohol-related problems among adolescents and young adults during a specified time frame (3 years). On a scale of 0 (never) to 4 (more than 10 times), participants indicated how often they experienced each alcohol-related problem.

Personality questionnaires and the CTQ-SF were assessed at T1, while the M DMQ-R, ABS, and RAPI were completed at T2. The AIS was answered at both T1 and T2. All the instruments showed good psychometric properties in previous studies with Spanish populations (see the manuals and articles indicated for each instrument).

\section{Data Analysis}

Missing Data. The scores of the participants with more than $5 \%$ of missing values in a questionnaire were deleted $(n=2)$, while missing values in a questionnaire lower than $5 \%$ were replaced with the mean score for the remaining items in that scale.

Descriptive Analysis and Internal Consistency of Scales. The means and standard deviations of personality dimensions, child maltreatment, drinking motives, antisocial behavior and alcohol consumptions were calculated. Gender differences were analyzed by Student's $t$-and Cohen's $d$ tests (Cohen, 1992). Cronbach's alpha was also calculated for each scale.

Exploratory Factor Analysis. To identify an integrated structure of normal personality, an exploratory factor analysis (EFA) with the assessed personality dimensions from different biodispositional models was performed (for a similar procedure, see Markon et al., 2005). We used principal axes analysis with oblimin rotation. A parallel analysis was carried out to select the number of retained factors. The regression scores for each factor were calculated and were later used in the path analysis.

Path Analyses. The EQS 6.1 (Bentler and Wu, 1995) software was used to perform the path analyses. First, we performed a Confirmatory Test of Complete Mediation (see James et al., 2006) in which the relationships between personality and alcohol outcomes were fully mediated by motives and antisocial behavior, and the maltreatment and alcohol outcomes relationships were fully mediated by personality (see Current Study for more detailed hypotheses). To control the effects of gender and alcohol use at T1, these variables were also covaried to all the variables of $\mathrm{T} 1$ and $\mathrm{T} 2$. The suggestions obtained from the Lagrange multiplier (LM) and Walt tests were taken into account to include, or to remove, additional paths to those hypothesized in the model (Byrne, 2006). Second, once the model was adjusted, we tested a partial mediation model to confirm or reject complete mediations. Essentially, we tested the direct paths between the variables when the indirect effects indicated complete mediation. If a coefficient was significant, mediation was partial; if it was not, complete mediation was confirmed (see MacKinnon, 2008, p. 72).

Given the non normality in the data, robust methods were used. The model's goodness-of-fit was evaluated using the following fit indices: the Satorra-Bentler chi-squared $\left(\mathrm{s}-\mathrm{B} \chi^{2}\right)$, the normed chi-squared $\left(\mathrm{s}-\mathrm{B} \chi^{2} / \mathrm{df}\right)$, the comparative fit index (CFI), the incremental fit index (IFI), the McDonald Fit Index (MFI), and the root mean square error of approximation (RMSEA). For a model to show a good fit, the ${ }_{\mathrm{S}-\mathrm{B}} \chi^{2}$ must be non significant, the normed $\mathrm{S}-\mathrm{B} \chi^{2}$ must be between 1 and 2, CFI, IFI, and MFI must be 0.95 or higher, and RMSEA must be 0.05 or lower (Byrne, 2006). 


\section{RESULTS}

The descriptive analyses showed that alcohol consumption was concentrated at the weekend. In addition, men drank more, reported more physical and emotional neglect, more coping-with-depression motives, and were more disinhibited (lower agreeableness and reward dependence, and higher psychoticism, sensitivity to reward, and antisocial behavior) than women. Women scored significantly higher in negative emotionality dimensions (neuroticism, harm avoidance, and sensitivity to punishment; see Table 1). The Cronbach's alpha of all the scales indicated a score close to or higher than the acceptable cut offs of 0.70 and 0.60 (for scales with $<10$ items; Loewenthal, 1996), except for the physical neglect scale (see Table 1).

When the EFA was performed, the chi-squared $\left(\chi^{2}=1,871.31, \mathrm{df}=91, p<0.001\right)$ and the Kaiser-MeyerOklin $(=0.75)$ indicated that the extraction method used was adequate for the data. The parallel analysis suggested retaining 4 factors, which accounted for $67.9 \%$ of total variance. These factors were labeled as negative emotionality, disagreeable disinhibition, positive emotionality, and unconscientious disinhibition (see Markon et al., 2005). The factor loadings of the personality scales are provided in Table 2 .

The hypothesized complete mediation model showed fit indices lower than 0.95 and ${ }_{\mathrm{S}-\mathrm{B}} \chi^{2}$ was non significant. After adding the specifications suggested by the LM and Walt tests, the fit indices were good $\left({ }_{\mathrm{s}-\mathrm{B}} \chi^{2}=86.62\right.$, $\mathrm{df}=67$, $p=0.054 ; \quad$ s-B $\chi^{2} / \mathrm{df}=1.29 ; \quad$ CFI $=0.980 ; \quad$ IFI $=0.981$, MFI $=0.969 ;$ RMSEA $=0.031$ ). The differences between the hypothesized model and the final model were the following: (i) sexual abuse did not relate to any dependent variable in the path analysis, so it was omitted; (ii) coping-with-anxiety motives were not associated with alcohol-related problems; (iii) coping-with-anxiety motives were marginally related $(\beta=0.11, p=0.07)$ to alcohol use

Table 1. Means and SD for the Assessed Variables, $p$-Values, and Cohen's $d$ Associated with Gender

\begin{tabular}{|c|c|c|c|c|c|c|}
\hline & $\begin{array}{l}\text { Cronbach's alphas } \\
\qquad(N=314)\end{array}$ & $\begin{array}{c}\text { Total sample } \\
\text { Mean }(\mathrm{SD})(N=314)\end{array}$ & $\begin{array}{c}\text { Men } \\
\text { Mean }(\mathrm{SD})(\mathrm{N}=121)\end{array}$ & $\begin{array}{c}\text { Women } \\
\text { Mean }(\mathrm{SD})(\mathrm{N}=193)\end{array}$ & $\begin{array}{l}t \text {-Test } \\
(p)\end{array}$ & $\begin{array}{l}\text { Cohen's } \\
\text { (d) }\end{array}$ \\
\hline \multicolumn{7}{|l|}{ Time 1} \\
\hline \multicolumn{7}{|l|}{ CTQ-SF } \\
\hline Emotional abuse & 0.80 & $6.58(2.68)$ & $6.31(2.15)$ & $6.75(2.95)$ & ns & 0.17 \\
\hline Emotional neglect & 0.82 & $8.04(3.05)$ & $8.72(3.24)$ & $7.62(2.85)$ & $<0.01$ & 0.36 \\
\hline Sexual abuse & 0.92 & $5.39(1.81)$ & $5.20(1.42)$ & $5.50(2.02)$ & ns & 0.17 \\
\hline Physical abuse & 0.52 & $5.33(1.02)$ & $5.39(1.03)$ & $5.30(1.02)$ & ns & 0.09 \\
\hline Physical neglect & 0.21 & $5.71(1.25)$ & $5.97(1.40)$ & $5.54(1.13)$ & $<0.01$ & 0.34 \\
\hline \multicolumn{7}{|l|}{ NEO-FFI } \\
\hline Neuroticism & 0.83 & $19.49(7.78)$ & $16.45(7.39)$ & $21.40(7.42)$ & $<0.001$ & 0.67 \\
\hline Extraversion & 0.79 & $30.99(6.46)$ & $30.69(6.20)$ & $31.18(6.62)$ & ns & 0.08 \\
\hline Openness & 0.72 & $28.99(6.14)$ & $28.50(6.50)$ & $29.30(5.90)$ & ns & 0.13 \\
\hline Agreeableness & 0.79 & $33.08(6.15)$ & $31.17(6.62)$ & $34.27(5.53)$ & $<0.001$ & 0.51 \\
\hline Conscientiousness & 0.86 & $29.17(7.40)$ & $28.35(7.43)$ & $29.68(7.35)$ & ns & 0.18 \\
\hline \multicolumn{7}{|l|}{ TCl-R } \\
\hline Harm avoidance & 0.85 & $15.20(6.45)$ & $13.25(6.23)$ & $16.42(6.30)$ & $<0.001$ & 0.51 \\
\hline Reward dependence & 0.69 & $17.01(3.59)$ & $15.26(3.61)$ & $18.11(3.12)$ & $<0.001$ & 0.84 \\
\hline Novelty seeking & 0.77 & $21.25(5.83)$ & $21.45(6.25)$ & $21.11(5.56)$ & ns & 0.06 \\
\hline Persistence & 0.60 & $4.31(1.93)$ & $4.11(1.89)$ & $4.43(1.95)$ & ns & 0.17 \\
\hline \multicolumn{7}{|l|}{ EPQ-RS } \\
\hline Neuroticism & 0.83 & $4.03(2.27)$ & $3.29(2.95)$ & $4.49(3.38)$ & $<0.01$ & 0.38 \\
\hline Psychoticism & 0.73 & $3.15(2.55)$ & $3.83(2.69)$ & $2.72(2.37)$ & $<0.001$ & 0.44 \\
\hline Extraversion & 0.75 & $9.14(2.53)$ & $8.98(2.68)$ & $9.24(2.43)$ & ns & 0.10 \\
\hline \multicolumn{7}{|l|}{ SPSRQ-SF } \\
\hline Sensitivity to punishment & 0.83 & $5.00(3.62)$ & $4.48(3.38)$ & $5.32(3.74)$ & $<0.05$ & 0.24 \\
\hline Sensitivity to reward & 0.80 & $6.38(3.86)$ & $8.03(3.75)$ & $5.34(3.56)$ & $<0.001$ & 0.74 \\
\hline \multicolumn{7}{|l|}{ Time 2} \\
\hline \multicolumn{7}{|l|}{ M DMQ-R } \\
\hline Coping-with-depression & 0.91 & $1.32(0.50)$ & $1.40(0.58)$ & $1.27(0.44)$ & $<0.05$ & 0.25 \\
\hline Coping-with-anxiety & 0.66 & $1.45(0.54)$ & $1.51(0.61)$ & $1.40(0.49)$ & ns & 0.20 \\
\hline Enhancement & 0.85 & $2.17(0.90)$ & $2.24(0.91)$ & $2.12(0.89)$ & ns & 0.13 \\
\hline \multicolumn{7}{|l|}{ Antisocial Behavior Scale } \\
\hline Antisocial behavior & 0.88 & $44.24(7.13)$ & 47.35 (8.60) & $42.29(5.17)$ & $<0.001$ & 0.71 \\
\hline \multicolumn{7}{|l|}{ Alcohol use } \\
\hline SDU during the week & - & $1.55(2.92)$ & $2.55(3.95)$ & $0.92(1.76)$ & $<0.001$ & 0.53 \\
\hline $\begin{array}{l}\text { SDU at the weekend } \\
\text { RAPI }\end{array}$ & - & $10.20(8.35)$ & $11.36(7.64)$ & $7.24(4.74)$ & $<0.001$ & 0.65 \\
\hline Alcohol-related problems & 0.90 & $7.24(9.11)$ & $9.65(11.21)$ & $5.73(7.13)$ & $<0.001$ & 0.42 \\
\hline
\end{tabular}

Rank anchors Childhood Trauma Questionnaire-Short Form (CTQ-SF) scales: 5-25; NEO-Five-Factor Inventory (NEO-FFI) scales: 0-48; Harm avoidance: 0-35; Reward Dependence: 0-24; Novelty Seeking: 0-40; Persistence: 0-8; Eysenck Personality Questionnaire-Revised (EPQ-RS) Scales: 0-12; Sensitivity to Punishment: 0-14; Sensitivity to Reward: 0-17; Modified Drinking Motives Questionnaire (M DMQ-R) scales: 1-5; Antisocial behavior: 35140; Alcohol-related problems: 0-92. Cohen's $d$ values of $0.20,0.50$, and 0.80 correspond to small, medium, and large effect sizes, respectively (Cohen, 1992). 
Table 2. Principal Axis Analysis with Oblimin Rotation of the Personality Scales

\begin{tabular}{|c|c|c|c|c|}
\hline & $\begin{array}{c}\text { Negative } \\
\text { emotionality }\end{array}$ & $\begin{array}{l}\text { Disagreeable } \\
\text { disinhibition }\end{array}$ & $\begin{array}{c}\text { Positive } \\
\text { emotionality }\end{array}$ & $\begin{array}{l}\text { Unconscientious } \\
\text { disinhibition }\end{array}$ \\
\hline Neuroticism (NEO-FFI) & 0.89 & 0.03 & 0.13 & -0.00 \\
\hline Harm avoidance (TCl-R) & 0.76 & -0.23 & -0.27 & 0.08 \\
\hline Neuroticism (EPQ-RS) & 0.76 & 0.13 & 0.11 & -0.05 \\
\hline Sensitivity to punishment (SPSRQ-SF) & 0.65 & -0.02 & -0.18 & 0.06 \\
\hline Agreeableness (NEO-FFI) & -0.26 & -0.67 & 0.15 & 0.02 \\
\hline Reward dependence (TCI-R) & 0.24 & -0.64 & 0.44 & -0.16 \\
\hline Sensitivity to reward (SPSRQ-SF) & 0.02 & 0.59 & 0.22 & -0.25 \\
\hline Psychoticism (EPQ-RS) & -0.05 & 0.50 & 0.17 & 0.25 \\
\hline Novelty seeking (TCl-R) & -0.08 & 0.24 & 0.69 & 0.32 \\
\hline Extraversion (EPQ-RS) & -0.31 & -0.01 & 0.57 & -0.25 \\
\hline Extraversion (NEO-FFI) & -0.42 & -0.09 & 0.57 & -0.23 \\
\hline Openness (NEO-FFI) & 0.02 & -0.02 & 0.26 & 0.02 \\
\hline Conscientiousness NEO-FFI & -0.20 & -0.10 & -0.14 & -0.76 \\
\hline Persistence (TCl-R) & 0.07 & 0.09 & 0.01 & -0.70 \\
\hline Exp. Var. & $28.9 \%$ & $17.0 \%$ & $11.5 \%$ & $10.5 \%$ \\
\hline
\end{tabular}

Bold = Loadings higher than 0.30; Exp. Var. = Percentage of explained variance.

during the week; (iv) low unconscientious disinhibition did not predict coping-with-anxiety; (v) direct pathways from emotional abuse and physical neglect to alcoholrelated problems were added; and (vi) although the associations of maltreatment and personality variables were more exploratory, some specific associations between maltreatment and personality arose: emotional abuse - negative emotionality, emotional neglect-positive emotionality, physical abuse - unconscientious disinhibition, and physical neglect - disagreeable disinhibition. The final path analysis is presented in Fig. 1. The indirect effects are presented in Table 3. As hypothesized, personality was significantly related to alcohol outcomes through motives and antisocial behavior, while abuse was related to them through personality. In contrast to our hypotheses, neglect did not relate indirectly to alcohol outcomes, although a significant indirect effect on motives and antisocial behavior through personality was observed.

In addition, we tested a partial mediation model for those variables whose indirect effects indicated complete mediations (e.g., Negative emotionality $\rightarrow$ alcohol-related problems; or Emotional abuse $\rightarrow$ coping-with-depression, see Table 3). When direct pathways were added, none were significant, except between unconscientious disinhibition and drinking at the weekend $(\beta=-0.10, p<0.05)$. However, the significant correlations between the personality dimensions of disinhibition $(r=0.23, p<0.001)$ and the positive, but not significant, correlations between unconscientious disinhibition and drinking at the weekend $(r=0.08, p>0.05$; see Table $\mathrm{S} 1$ ) suggested that this negative coefficient was a suppression effect (Tu et al., 2008). As the new direct paths were nonsignificant, or simply reflected a suppression effect, and as their inclusion worsened the fit indices $\left(_{\mathrm{s}-\mathrm{B}} \chi^{2}=81.60\right.$, $\mathrm{df}=52, \quad p=0.005 ; \quad \mathrm{s}-\mathrm{B} \chi^{2} / \mathrm{df}=1.57 ; \quad \mathrm{CFI}=0.969 ;$ $\mathrm{IFI}=0.972, \mathrm{MFI}=0.954 ;$ RMSEA $=0.043)$, they were not included in the model. These results indicated that the described mediations were complete, as hypothesized, except for emotional abuse (partial mediation) and physical neglect (direct effect) on alcohol-related problems, and emotional neglect (no effect) on alcohol outcomes.

\section{DISCUSSION}

The main aim of the present study was 2-fold: (1) to identify the different etiological pathways involved in the development of alcohol use and alcohol-related problems; (2) to examine the role that child maltreatment, personality, and drinking motives play in these pathways by means of a 5 -year prospective design. For clarification purposes, the descriptive and personality structure results will be briefly discussed in the first place.

The descriptive analysis showed a similar pattern of results to those described in previous studies on alcohol consumption (National Plan of Drugs, 2013; Young-Wolff et al., 2011), personality (Gutiérrez-Zotes et al., 2004; Ortet et al., 2001; Torrubia et al., 2001), and maltreatment (Gilbert et al., 2009), suggesting that our findings were generalizable, despite the sample attrition. Nonetheless, we found a very low rate of informed sexual abuse in our sample $(93 \%$ scored "never true" in the 5 sexual abuse scale items) as compared with previous studies (Pereda and Forns, 2007). This fact may explain why we did not find gender differences and why sexual abuse was not associated with any variable in the subsequent path analysis, conversely to what is usually found (Gilbert et al., 2009; Tonmyr et al., 2010). In relation to the personality structure, we found a 4-factor solution that was virtually identical to that found by Markon and colleagues (2005). It embraces the broad personality domains of negative emotionality, disagreeable disinhibition, positive emotionality, and unconscientious disinhibition. These factors are closely linked to the FFM of personality except for openness to experience, probably because this domain is not well-represented in other personality models apart from the FFM (Markon et al., 2005). Yet, as the role of openness on 
$11 *$

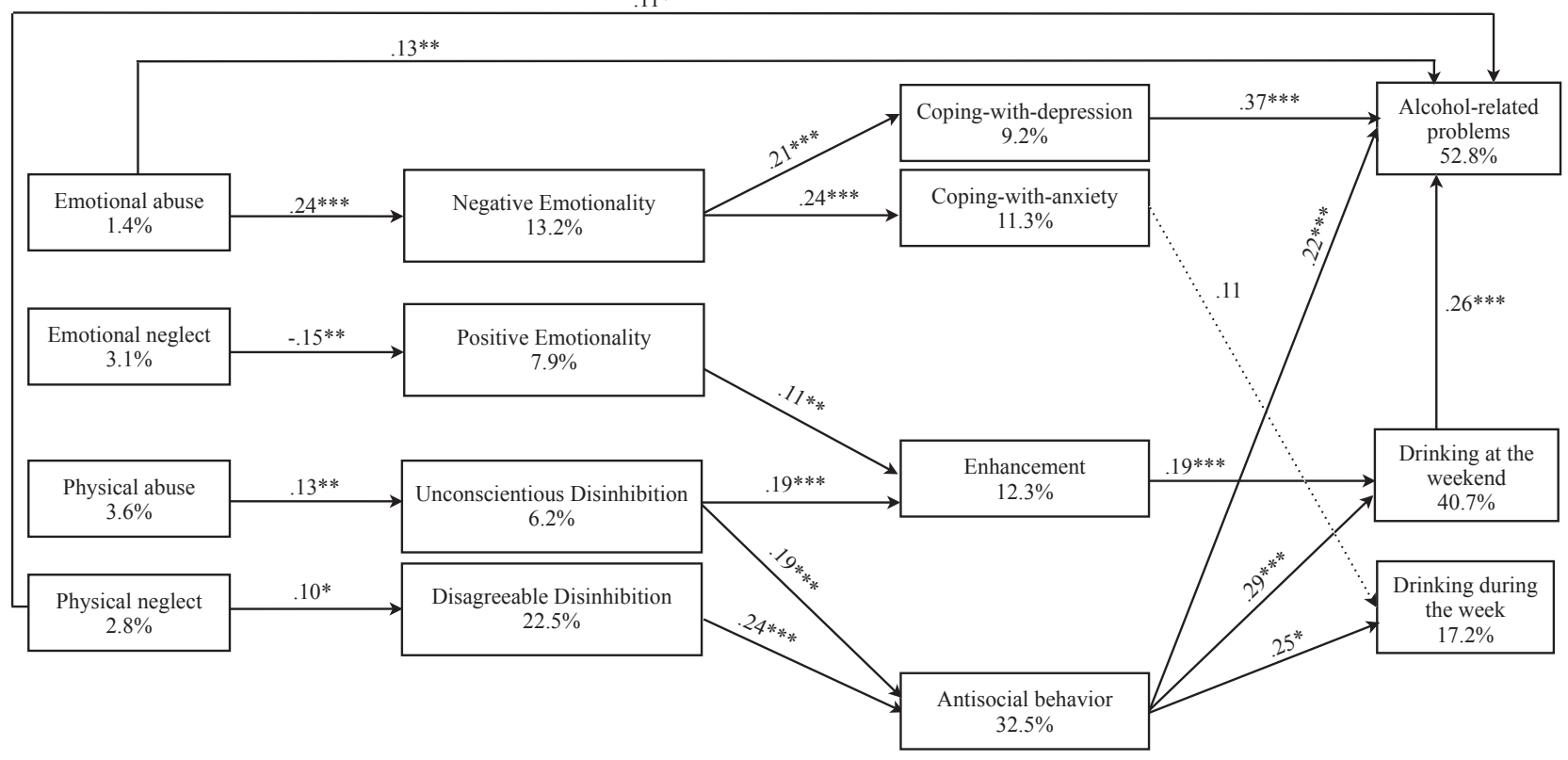

Fig. 1. Path model depicting child maltreatment (Time 1 [T1]), personality factors (T1), internal drinking motives (Time 2 [T2]), antisocial behavior (T2), drinking during the week and at the weekend in Standard Drink Units (SDU; T2), and alcohol-related problems (T2). On the lines we find the standardized solutions, which are significant at $* p<0.05, * * p<0.01$, and $* * * p<0.001$. On the discontinuous line, there are the tendencies at $p=0.07$. In the boxes, total variance is explained. The intercorrelations among types of child maltreatment, personality domains, SDU at T2, drinking motives, and their correlations with antisocial behavior, were introduced into the model, but they are not included in the figure to facilitate its interpretation. In addition, gender was covaried to all the observable variables of $\mathrm{T} 1$ and $\mathrm{T} 2$ to control spurious associations between them that may arise simply because of their uneven distributions across genders. The same treatment was given for the alcohol use variable at T1. This allows us to control that the associations with alcohol at T2 reflect a real prospective association rather than associations that are due to previous alcohol use. Specifically, we found that gender was significantly related with emotional neglect $(\beta=-0.18, p=0.003)$, physical neglect $(\beta=-0.16, p=0.005)$, negative emotionality $(\beta=0.25, p=0.000)$, disagreeable disinhibition $(\beta=-0.33, p=0.000)$, positive emotionality $(\beta=0.13, p=0.025)$ coping-with-depression $(\beta=-0.15, p=0.009)$, SDU during the week (T1: $\beta=-0.16, p=0.009$; T2: $\beta=-0.17, p=0.005$ ) and at the weekend (T1: $\beta=-0.19, p=0.002 ;$ T2: $\beta=-0.16, p=0.004$ ), and with antisocial behavior $(\beta=-0.18, p=0.001)$. $1=$ men, $2=$ women. SDU during the week at T1 was related to negative emotionality $(\beta=0.10, p=0.042)$, disagreeable disinhibition ( $\beta=0.10, p=0.029)$, unconscientious disinhibition $(\beta=0.16, p=0.032)$, coping-with-anxiety $(\beta=0.14, p=0.029)$, and SDU at the weekend at T1 was related to physical abuse $(\beta=0.19, p=0.008)$, disagreeable disinhibition $(\beta=0.18, p=0.002)$, positive emotionality $(\beta=0.23$, $p=0.000)$, enhancement $(\beta=0.23, p=0.003)$, SDU at the weekend (T2) $(\beta=0.27, p=0.000)$, and antisocial behavior $(\beta=0.22, p=0.008)$.

Table 3. Indirect Effects of the Final Path Analysis

\begin{tabular}{|c|c|c|c|c|c|}
\hline Path & St. beta & $p$ & Path & St. beta & $p$ \\
\hline Negative affect regulation & & & Positive affect regulation & & \\
\hline Emotional abuse $\rightarrow$ coping-with-depression & 0.050 & 0.001 & Physical abuse $\rightarrow$ enhancement & 0.024 & 0.032 \\
\hline Emotional abuse $\rightarrow$ coping-with-anxiety & 0.057 & 0.000 & Emotional neglect $\rightarrow$ enhancement & -0.016 & 0.034 \\
\hline $\begin{array}{l}\text { Emotional abuse } \rightarrow \text { Standard Drink Units (SDUs) } \\
\text { during the week }\end{array}$ & 0.007 & 0.084 & Emotional neglect $\rightarrow$ SDUs at the weekend & -0.003 & 0.071 \\
\hline Emotional abuse $\rightarrow$ alcohol-related problems & 0.019 & 0.003 & Emotional neglect $\rightarrow$ alcohol-related problems & -0.001 & 0.115 \\
\hline Negative emotionality $\rightarrow$ SDUs during the week & 0.027 & 0.075 & Positive emotionality $\rightarrow$ SDUs at the weekend & 0.021 & 0.030 \\
\hline Negative emotionality $\rightarrow$ alcohol-related problems & 0.079 & 0.001 & Positive emotionality $\rightarrow$ alcohol-related problems & 0.006 & 0.068 \\
\hline $\begin{array}{l}\text { Common paths shared by positive affect regulation } \\
\text { and deviant proneness }\end{array}$ & & & Enhancement $\rightarrow$ alcohol-related problems & 0.049 & 0.009 \\
\hline Physical abuse $\rightarrow$ SDUs during the week & 0.005 & 0.081 & Deviance proneness & & \\
\hline Physical abuse $\rightarrow$ SDUs at the weekend & 0.011 & 0.042 & Physical abuse $\rightarrow$ antisocial behavior & 0.023 & 0.032 \\
\hline Physical abuse $\rightarrow$ alcohol-related problems & 0.008 & 0.047 & Physical neglect $\rightarrow$ antisocial behavior & 0.024 & 0.048 \\
\hline Physical neglect $\rightarrow$ SDUs during the week & 0.005 & 0.112 & Physical neglect $\rightarrow$ SDUs at the weekend & 0.007 & 0.073 \\
\hline Physical neglect $\rightarrow$ alcohol-related problems & 0.007 & 0.068 & Unconscientious disinhibition $\rightarrow$ SDUs during the week & 0.036 & 0.024 \\
\hline Unconscientious disinhibition $\rightarrow$ SDUs at the weekend & 0.089 & 0.001 & Disagreeable disinhibition $\rightarrow$ SDUs during the week & 0.046 & 0.029 \\
\hline $\begin{array}{l}\text { Unconscientious disinhibition } \rightarrow \text { alcohol-related } \\
\text { problems }\end{array}$ & 0.064 & 0.001 & Disagreeable disinhibition $\rightarrow$ alcohol-related problems & 0.070 & 0.001 \\
\hline Disagreeable disinhibition $\rightarrow$ SDUs at the weekend & 0.068 & 0.002 & Antisocial behavior $\rightarrow$ alcohol-related problems & 0.075 & 0.003 \\
\hline
\end{tabular}

alcohol use and abuse is negligible (Kotov et al., 2010), this 4-factor solution was retained.

Regarding the different etiological pathways involved in the development of alcohol use and misuse, our results showed the co-occurrence of the 3 main paths characterized by specific personality, motives, and child maltreatment variables. Although the present study mainly focuses on nonpathological alcohol consumption in relatively healthy 
young adults, the described pathways clearly resemble those proposed by Sher and colleagues (2005) for the development of alcohol use disorders: negative affect regulation, positive affect regulation, and deviance proneness. These data suggest that some of the variables and processes involved in nonpathological alcohol use are also involved in alcohol use disorders, just as quantitative genetic studies have previously shown (e.g., Kendler et al., 2010).

The negative affect regulation pathway was related to more problematic alcohol use, in which negative emotionality and coping motives would play a prominent role. Specifically, negative emotionality was associated predictively with alcohol-related problems that developed 5 years later through coping-with-depression drinking motives. Alcohol-related problems were clearly predicted by coping-with-depression, but not by coping-with-anxiety motives, probably because coping motives correlated well with each other (see Table S1). However, coping-with-anxiety motives were marginally related to alcohol use during the week, which has been previously recorded in studies with the Spanish general population (Mezquita et al., 2011). One possible explanation is that coping-with-anxiety drinkers may drink alcohol during the week to deal with stress produced by daily tasks. Nevertheless, other studies about drinking motives and the context in which people drink alcohol would be necessary to test these hypotheses. In any case, our results suggest that coping-with-depression drinking motives play a more relevant role in the negative affect regulation pathway than coping-with-anxiety motives.

The positive affect regulation pathway was associated with more recreational alcohol use in which the personality characteristics of impulsivity and sensitivity to reward may play a more prominent role through enhancement motives. Specifically, positive emotionality and unconscientious disinhibition predicted alcohol use at weekends through enhancement drinking motives. Moreover, these motives were also associated with alcohol-related problems through their relation to drinking at the weekend. This finding falls in line with previous studies, which suggested a meditational effect of alcohol consumption in the relationship between enhancement motives and alcohol-related problems (Cooper, 1994; Mezquita et al., 2010), and emphasizes the importance of differentiating between drinking during the week and at the weekend (Mezquita et al., 2011).

Finally, the deviance proneness pathway was associated with all the alcohol-related outcomes through antisocial behavior, even when the effect of motives was controlled for. Specifically, unconscientious disinhibition and disagreeable disinhibition related prospectively to antisocial behavior 5 years later, and both personality domains indirectly predict drinking during the week through antisocial behavior. The same mediation effect of antisocial behavior was observed between disagreeable disinhibition and drinking at the weekend. Remarkably, antisocial behavior still predicted alcoholrelated problems after controlling for alcohol use at T2, which indicated a more problematic alcohol use pattern associated with this pathway that was not fully mediated by the larger quantity of alcohol consumed.

The present study also provides information about the role of maltreatment on alcohol etiological pathways. Specifically, emotional abuse was indirectly associated with alcohol-related problems through negative emotionality and coping-with-depression motives (negative affect regulation pathway). This finding complements previous studies in which coping-with-depression mediated the relationship between child abuse and drinking consequences (Goldstein et al., 2010), and suggests that negative emotionality could be a mediator mechanism among maltreatment, coping motives, and subsequent alcohol-related problems. The fact that emotional abuse also had a direct effect on alcoholrelated problems highlights the importance of early life stressors on the subsequent development of problematic alcohol use (Enoch, 2011), and the further examination of other mechanisms beyond personality and motives that may account for these associations is worthwhile.

In addition, physical abuse indirectly predicted both SDUs consumed at weekends and alcohol-related problems through unconscientious disinhibition, suggesting an influence of physical abuse on both the positive affect regulation and deviance proneness pathways. Physical neglect directly predicted alcohol-related problems. Although this type of maltreatment is also indirectly related to antisocial behavior through disagreeable disinhibition, no significant indirect effect on drinking quantity was found. Finally, emotional neglect was not directly or indirectly associated with alcohol use, although it showed an indirect inverse relation to enhancement motives through positive emotionality. This finding suggests that emotional neglect is associated with introversion and, as expected, it is less likely that introverted young adults report enhancement motives. To summarize, the non significant indirect relationships observed between neglect (physical and psychological) and alcohol outcomes (drinking quantity and alcohol-related problems) suggest that harsher types of maltreatment (abuse vs. neglect) might be more relevant in the etiological pathways proposed by Sher and colleagues (2005).

Our data also reflected a certain degree of specificity between different types of maltreatment and particular personality domains, which deserves more attention. Specifically, emotional abuse was related mainly to negative emotionality, whereas emotional neglect was associated inversely with positive emotionality. Furthermore, physical abuse was related to unconscientious disinhibition, whereas physical neglect was associated with disagreeable disinhibition. Although studies into the association between specific types of maltreatment and personality are scarce, similar results have been previously documented. Nederlof and colleagues (2010) found that emotional abuse is specifically related to neuroticism, whereas physical abuse is specifically associated with low agreeableness and dissocial behavior in a sample of incarcerated boys. Studies on psychological and personality disorders have also suggested similar specific 
relationships. On the one hand, the Antisocial Personality Disorder, which is related to disinhibition characteristics, is associated specifically with physical abuse, whereas Cluster $\mathrm{C}$ personality disorders and the Borderline Personality Disorder, characterized by emotional dysregulation, and negative emotionality characteristics have been related mainly to emotional abuse (Bernstein et al., 1998; Lobbestael et al., 2010). On the other hand, emotional abuse, rather than other child maltreatment types, has been associated with internalizing symptoms (Trickett et al., 2011; Wright et al., 2009). In short, although all types of maltreatment seem to have a pervasive effect on personality and psychopathological development (Norman et al., 2012), a certain degree of specificity according to different types of maltreatment seems to exist, with emotional maltreatment being linked more to internalizing-related personality/disorders, and physical maltreatment being associated more with externalizing-related personality/disorders. Although our results tend to agree with these findings, the relative specificity of the relationships between some maltreatment types and certain personality dimensions were found in the post hoc analysis, so they clearly deserve replication in future studies.

The present research work has several limitations. First, our sample presented a fairly substantial level of attrition, although those participants who were retained differed from those who dropped out in only 4 of the 22 variables assessed. Second, despite there being evidence that self-report surveys of alcohol use are potentially and reasonably accurate measures of drinking levels (Northcote and Livingston, 2011), the addition of more objective measures (e.g., breath alcohol concentration) is recommended. These measures may also help to control possible gender differences in alcohol use. In addition, the use of other alcohol-related measures (e.g., binge drinking or DSM diagnoses) and clinical samples are recommended to depict pathways for more severe and pathological alcohol use. Third, the physical neglect scale shows low alpha reliability in our sample. This result contrasts with studies done with clinical samples, which found adequate reliabilities (e.g., Hernández et al., 2013), but it is similar to other studies done with undergraduate samples (Gerdner and Allgulander, 2009). In any case, the data related to physical neglect should be interpreted with caution. Fourth, although this is a prospective study, some variables were assessed at the same time (e.g., child maltreatment and personality; and drinking motives, and alcohol-related outcomes), Fifth, although personality and maltreatment predicted motives and alcohol-related behaviors, causal interpretations cannot be inferred. For example, maltreatment might cause personality modifications (e.g., emotional abuse may increase emotional instability), however, personality may also cause maltreatment through a transactional evocative process (e.g., impulsive children can facilitate the use of physical punishments by parents), or the association may be attributed to a common factor (e.g., highly dis- inhibited parents would transmit disinhibited personality genes and punishment rearing styles to their children). An alternative explanation for these findings can be attributed to another limitation, the use of self-report measures, which can lead to a recall or interpretation bias, especially in the case of neuroticism (Leikas and Lindeman, 2009). For example, emotionality unstable participants may interpret both their child-rearing experiences and consequences of alcohol use more negatively. However, the specific relationships that we find between personality, apart from negative emotionality, and the different types of maltreatment do not seem to fit in with this explanation. Finally, the role of gender in the described pathways also deserves more attention (YoungWolff et al., 2011). Although we controlled for this variable in the analyses, the use of a larger sample is desirable to study these pathways (e.g., multigroup analysis) separately for men and women.

In summary, the results of the present research identify 3 co-occurring etiological pathways that are substantially similar to those proposed by Sher and colleagues (2005). The negative affect regulation pathway includes emotional abuse, negative emotionality, and coping-with-depression motives. The positive affect regulation pathway implies positive emotionality and unconscientious disinhibition personality characteristics, which predict a more recreational use of alcohol at weekends through its relationship to enhancement drinking motives. Finally, unconscientious disinhibition and disagreeable disinhibition predict alcohol outcomes through antisocial behavior in the deviance proneness pathway. Physical maltreatment influences the last 2 pathways. These data, together with other studies that describe the specific factors and processes involved in different pathways, may improve prevention and intervention programs for alcohol misuse; for example, developing programs designed to target different motivational processes and personality traits (Conrod et al., 2011).

\section{ACKNOWLEDGMENTS}

Funding for this study was provided by research projects PNSD2009-019 from the Spanish Ministry of Health, P1·1B2010-40 and P1·1B2011-47 from Bancaixa-Universitat Jaume I.

\section{REFERENCES}

Bailey JA, McCloskey LA (2005) Pathways to adolescent substance use among sexually abused girls. J Abnorm Child Psych 33:39-53.

Bentler PM, Wu EJC (1995) EQS for Windows User's Guide. Multivariate Software Inc, Encino, CA.

Bernstein DP, Stein JA, Handelsman L (1998) Predicting personality pathology among adult patients with substance use disorders: effects of childhood maltreatment. Addict Behav 23:855-868.

Byrne BM (2006) Structural Equation Modeling with EQS: Basic Concepts, Applications, and Programming. 2nd ed. Erlbaum, Mahwah, NJ.

Cohen J (1992) A power primer. Psychol Bull 110:155-159. 
Conrod PJ, Castellanos-Ryan N, MacKie C (2011) Long-term effects of a personality-targeted intervention to reduce alcohol use in adolescents. J Consult Clin Psychol 79:296-306.

Cooper ML (1994) Motivations for alcohol use among adolescents: development and validation of a four-factor model. Psychol Assess 6:117-128.

Cooper ML, Agocha VB, Sheldon MS (2000) A motivational perspective on risky behaviors: the role of personality and affect regulatory processes. J Pers 68:1059-1088.

Costa PT, McCrae RR (1999) Revised NEO Personality Inventory (NEOPI-R) and NEO Five-Factor Inventory (NEO-FFI). Professional Manual. TEA, Madrid.

Enoch MA (2011) The role of early life stress as a predictor for alcohol and drug dependence. Psychopharmacology 214:17-31.

Gerdner A, Allgulander C (2009) Psychometric properties of the Swedish version of the Childhood Trauma Questionnaire - Short Form (CTQ-SF). Nord J Psychiatry 63:160-170.

Gilbert R, Widom CS, Browne K, Fergusson D, Webb E, Janson S (2009) Burden and consequences of child maltreatment in high-income countries. Lancet 373:68-81.

Goldstein AL, Flett GL, Wekerle C (2010) Child maltreatment, alcohol use and drinking consequences among male and female college students: an examination of drinking motives as mediators. Addict Behav 35:636-639.

Grau E, Ortet G (1999) Personality traits and alcohol consumption in a sample of non-alcoholic women. Pers Indiv Differ 27:1057-1066.

Gutiérrez-Zotes JA, Bayón C, Montserrat C, Valero J, Labad A, Cloninger CR, Fernández-Aranda F (2004) Inventario del Temperamento y el Carácter-Revisado (TCI-R). Baremación y datos normativos en una muestra de población general. Actas Esp Psiquiatr 32: 8-15.

Hernández A, Gallardo-Pujol D, Pereda N, Arntz A, Bernstein DP, Gaviria AM, Labad A, Valero J, Gutiérrez-Zotes JA (2013) Initial validation of the Spanish childhood trauma questionnaire-short form: factor structure, reliability and association with parenting. $\mathbf{J}$ Interpers Violence 28: 1498-1518.

Ibáñez MI, Ruiperez MA, Villa H, Moya J, Ortet G (2008) Personality and alcohol use, in The SAGE Handbook of Personality Theory and Assessment, Vol 1: Personality Theories and Models (Boyle G, Matthews G, Saklofske D eds), pp 677-697. Sage Publications Inc, Thousand Oaks, CA.

James LR, Mulaik SA, Brett JM (2006) A tale of two methods. Organ Res Method 9:233-244.

Kendler KS, Myers J, Dick D, Prescott CA (2010) The relationship between genetic influences on alcohol dependence and on patterns of alcohol consumption. Alcohol Clin Exp Res 34:1058-1065.

Kendler KS, Prescott CA, Myers J, Neale MC (2003) The structure of genetic and environmental risk factors for common psychiatric and substance use disorders in men and women. Arch Gen Psychiatry 60:929-937.

Kotov R, Gamez W, Schmidt F, Watson D (2010) Linking "Big" personality traits to anxiety, depressive, and substance use disorders: a meta-analysis. Psychol Bull 136:768-821.

Krueger RF, Hicks BM, Patrick CJ, Carlson SR, Iacono WG, McGue M (2002) Etiologic connections among substance dependence, antisocial behavior and personality: modeling the externalizing spectrum. J Abnorm Psychol 111:411-424.

Kuntsche E, Knibbe R, Gmel G, Engels R (2005) Why do young people drink? A review of drinking motives. Clin Psychol Rev 25:841-861.

Kuntsche E, Knibbe R, Gmel G, Engels R (2006) Who drinks and why? A review of socio-demographic, personality, and contextual issues behind the drinking motives in young people. Addict Behav 31:1844-1857.

Kuntsche E, von Fischer M, Gmel G (2008) Personality factors and alcohol use: a mediator analysis of drinking motives. Pers Indiv Differ 45:796-800.

Leikas S, Lindeman M (2009) Personality, threat identification and emotional processing. Eur J Pers 23:455-474.

Lobbestael J, Arntz A, Bernstein DP (2010) Disentangling the relationship between different types of childhood maltreatment and personality disorders. J Pers Disord 24:285-295.

Loewenthal KM (1996) An Introduction to Psychological Tests and Scales. UCL Press Limited, London, UK.
López-Núñez C, Fernández-Artamendi S, Fernández-Hermida JR, Álvarez ÁC, Secades-Villa R (2012) Spanish adaptation and validation of the Rutgers Alcohol Problem Index (RAPI). Int $\mathbf{J}$ Clin Health Psychol 12:251-264

Lukasiewicz M, Neveu X, Blecha L, Falissard B, Reynaud M, Gasquet I (2008) Pathways to substance-related disorder: a structural model approach exploring the influence of temperament, character, and childhood adversity in a national cohort of prisoners. Alcohol Alcohol 43:287-295.

MacKinnon D (2008) Introduction to Statistical Mediation Analysis. Taylor \& Francis, New York, NY.

Markon KE, Krueger RF, Watson D (2005) Delineating the structure of normal and abnormal personality: an integrative hierarchical approach. $\mathbf{J}$ Pers Soc Psychol 88:139-157.

Mezquita L, Stewart SH, Ibáñez MI, Ruipérez MA, Villa H, Moya J, Ortet G (2011) Drinking motives in clinical and general populations. Eur Addict Res 17:250-261.

Mezquita L, Stewart SH, Ruipérez M (2010) Big-five personality domains predict internal drinking motives in young adults. Pers Indiv Differ 49:240-245.

Moran P, Coffey C, Chanen A, Mann A, Carlin JB, Patton GC (2010) Childhood sexual abuse and abnormal personality: a population-based study. Psychol Med 27:1-8.

National Plan of Drugs (2013) Encuesta Domiciliaria (EDADES) 2011-2012. Available at: http://www.pnsd.msc.es/Categoria2/observa/pdf/ EDADES2011.pdf. Accessed July 30, 2013.

Nederlof E, Van Der Ham JM, Dingemans PMJA, Oei TI (2010) The relation between dimensions of normal and pathological personality and childhood maltreatment in incarcerated boys. J Pers Disord 24:746-762.

Norman RE, Byambaa M, De R, Butchart A, Scott J, Vos T (2012) The long-term health consequences of child physical abuse, emotional abuse, and neglect: a systematic review and meta-analysis. PLoS Med 9. Available at: http://www.plosmedicine.org/article/fetchObject. action?uri $=$ info $\% 3$ Adoi $\% 2$ F $10.1371 \% 2$ Fjournal.pmed. $1001349 \&$ represe ntation $=$ PDF. Accessed April 32014.

Northcote J, Livingston M (2011) Accuracy of self-reported drinking: observational verification of 'last occasion' drink estimates of young adults. Alcohol Alcohol 46:709-713.

Ortet G, Ibáñez MI, Moro M, Silva F (2001) Versión corta del EPQ-R (EPQ-RS) [Short version of the EPQ-R (EPQ-RS)]. TEA Ediciones, Madrid.

Oshri A, Rogosch FA, Cicchetti D (2013) Child maltreatment and mediating influences of childhood personality types on the development of adolescent psychopathology. J Clin Child Adolesc Psychol 42:287-301.

Pereda N, Forns M (2007) Prevalencia y características del abuso sexual infantil en estudiantes universitarios españoles. Child Abuse Negl 31: 417-426.

Rodríguez-Martos A, Gual A, Llopis JJ (1999) The "standard drink unit" as a simplified recording system of alcohol consumption and its measurement in Spain. Med Clin (Barc) 112:446-450.

Rogosch FA, Cicchetti D (2004) Child maltreatment and emergent personality organization: perspectives from the five-factor model. J Abnorm Child Psychol 32:123-145.

Ruiz MA, Pincus AL, Dickinson KA (2003) NEO PI-R predictors of alcohol use and alcohol-related problems. J Pers Assess 81:226-236.

Sher KJ, Grekin ER, Williams NA (2005) The development of alcohol use disorders. Annu Rev Clin Psychol 1:493-523.

Shin SH, Hong HG, Wills TA (2012) An examination of pathways from childhood maltreatment to adolescent binge drinking. Am J Addict 21:202-209.

Silva F, Martínez-Arias R, Moro M, Ortet G (1996) Dimensions of interpersonal orientation: description and construct validation of the Spanish assessment kit. Eur Psychol 1:187-199.

Tonmyr L, Thornton T, Draca J, Wekerle C (2010) A review of childhood maltreatment and adolescent substance use relationship. Curr Psychiatry Rev 6:223-234. 
Torrubia R, Ávila C, Moltó J, Caseras X (2001) The Sensitivity to Punishment and Sensitivity to Reward Questionnaire (SPSRQ) as a measure of Gray's anxiety and impulsivity dimensions. Pers Indiv Differ 31:837-862.

Trickett PK, Kim K, Prindle J (2011) Variations in emotional abuse experiences among multiply maltreated young adolescents and relations with developmental outcomes. Child Abuse Negl 35:876-886.

Tu YK, Gunnell D, Gilthorpe MS (2008) Simpson's Paradox, Lord's Paradox, and Suppression Effects are the same phenomenon - the reversal paradox. Emerg Themes Epidemiol 5:2.

World Health Organization (WHO) (2011) Global Status Report on Alcohol and Health. WHO, Geneva.

Wright MO, Crawford E, Del Castillo D (2009) Childhood emotional maltreatment and later psychological distress among college students: the mediating role of maladaptive schemas. Child Abuse Negl 33:5968.

Young-Wolff KC, Enoch MA, Prescott CA (2011) The influence of geneenvironment interactions on alcohol consumption and alcohol use disorders: a comprehensive review. Clin Psychol Rev 31:800-816.

\section{SUPPORTING INFORMATION}

Additional Supporting Information may be found in the online version of this article:

Table S1. Pearson correlations between the variables included in the initial path analysis. 